\title{
Mode II fracture characterization of toughened epoxy resin composites
}

\author{
Michał Barcikowski • Katarzyna Rybkowska
}

Received: 28 February 2021 / Accepted: 5 January 2022 / Published online: 17 January 2022

(C) The Author(s) 2022

\begin{abstract}
Epoxy resin used commonly as a matrix for polymer composite materials has good handling properties, but is too brittle. That is why various modifiers are used to increase the flexibility of products based on epoxy resin. This leads to two issues: how to efficiently increase the toughness of the resin without impacting significantly other properties, as well as how to measure the toughness in composite materials. The work aimed to show how the addition of a reactive rubber modifier will affect the fracture toughness of the obtained laminates during the longitudinal shear test (Mode II fracture). In total, three epoxy-glass laminates with different matrices were made and subjected to the End-Notched Flexure test according to ASTM D7905/D7905M standard: (1) the basic matrix of Epidian 6 resin, (2) Epidian 6 modified with the addition of $10 \%$ of Albipox 1000 reactive liquid rubber and (3) Epidian 6 modified with the addition of $10 \%$ of Hypro 1300X16 ATBN reactive liquid rubber. Based on the obtained results, it can be seen that the modulus of elasticity for the modified laminates was decreased compared to the laminate of pure epoxy resin (by $\sim 25 \%$ ). However, the addition of reactive rubbers increased the fracture toughness of the modified epoxy-glass laminates in the Mode II longitudinal shear test $\left(G_{I I c}\right)$ by $\sim 40-60 \%$. Thus the
\end{abstract}

M. Barcikowski $(\bowtie) \cdot K$. Rybkowska Faculty of Mechanical Engineering, Wrocław University of Science and Technology, Wrocław, Poland e-mail: michal.barcikowski@pwr.edu.pl benefits of modification outweigh the drawbacks if fracture toughness is an important designing consideration in a given application. The applicability of ENF method is successfully tested, but potential drawbacks are indicated-careful control of specimen thickness is necessary.

Keywords Fiber-reinforced plastics - Epoxy resin . Reactive liquid polymers · End-notched flexure · Mode II fracture toughness · Energy release coefficient

\begin{tabular}{|c|c|}
\hline \multicolumn{2}{|c|}{ Abbreviations } \\
\hline ATBN & Amine-terminated butadiene nitrile rubber \\
\hline CTBN & $\begin{array}{l}\text { Carboxyl-terminated butadiene nitrile } \\
\text { rubber }\end{array}$ \\
\hline DCB & Double cantilever beam \\
\hline ENF & End-notched flexure \\
\hline FRP & Fiber-reinforced plastic \\
\hline HTBN & $\begin{array}{l}\text { Hydroxyl-terminated butadiene nitrile } \\
\text { rubber }\end{array}$ \\
\hline NBR & Nitrile-butadiene rubber \\
\hline NPC & Non-pre-cracked \\
\hline $\begin{array}{l}\text { NPC- } \\
\mathrm{CC}\end{array}$ & Non-pre-cracked compliance calibration \\
\hline RLP & Reactive liquid polymer \\
\hline RLR & Reactive liquid rubber \\
\hline TETA & Triethylenetetramine \\
\hline
\end{tabular}




\section{Introduction}

Polymer composite materials, also known as fiberreinforced plastics (FRP) are nowadays widely used construction materials. They typically consist of reinforcing fibers (e.g. glass, carbon, aramid) embedded in a thermosetting matrix (e.g. unsaturated polyester or epoxy resin). The main advantages of FRP are high specific strength and modulus, as well as the ability to tailor the properties throughout the element to suit local needs. Thermosetting resins are used predominantly because of their ease of manufacture, as well as better temperature and creep resistance.

Epoxy resins are a widely used material in the industry, including in everyday life as adhesives or sealants, as well as in composite materials as a matrix. Apart from numerous advantages, they also have significant disadvantages - they are brittle and have a relatively low impact strength. This excludes them from many applications that require significant fracture toughness, i.e. impact and fatigue strength. Therefore, resin modifying additives (various polymers, often elastomers) were used to improve the fracture toughness and dynamic properties. One of the most commonly used methods to improve the fracture toughness parameters of resins is the addition of reactive liquid rubbers (RLR, also called reactive liquid polymers-RLP), which at the same time do not deteriorate the processing properties, nor final properties after curing (see, inter alia, Sultan and McGarry 1973; Ozturk et al. 2001; Chikhi et al. 2002; Kinloch et al. 2005; Unnikrishnan and Thachil 2006; Abadyan et al. 2011; Szymańska et al. 2018; Guo et al. 2019; Chae et al. 2020; Januszewski et al. 2021). Nowadays, it is a common method of increasing the efficiency of epoxy resins in the industry. Acrylonitrile-butadiene rubbers (NBR) are the most commonly used. An important aspect is the very good miscibility of the elastomer with liquid resin. Rubbery particles precipitate on curing, leading to the formation of a second phase due to an increase in the molecular weight of the resin. To obtain stable elastomer dispersions in epoxy resin, rubbers with the amine (ATBN), carboxyl (CTBN), and hydroxyl (HTBN) end groups are used. The elastomer particles should not be too small, as they prevent the propagation of microcracks. This has a significant impact on the impact strength of the resin composition. The disadvantages of rubber elastomers include the presence of structures with places susceptible to oxidizing agents and high temperature.

This success led to trials of using RLR for modification of other types of resins: phenolic (Kaynak and Cagatay 2006) as well as vinyl ester and unsaturated polyester (e.g. Kostański and Królikowski 1985; Crosbie and Phillips 1985a, b; McBain 1996; Ullet and Chartoff 1996; Barcikowski and Królikowski 2013; Barcikowski et al. 2017). Despite that long-term use, neither the specifics of its mechanism nor fracture mechanics are fully understood (Unnikrishnan and Thachil 2006; Ullet and Chartoff 1996).

Destruction of materials made of layered composites, i.e. laminates, is often associated with the development of an interlaminar crack, called delamination. They are one of the most dangerous types of damage to structural elements. They happen suddenly and violently, and they can be associated with huge material and non-material losses. Cracking in fiberreinforced laminates generally occurs between the individual layers. It begins in the matrix of the composite and leads to the weakening of the interaction between the polymer and the fibers. The fibers are the last to be destroyed, which leads to further propagation of delamination (Ochelski 2004). Characterization of the resistance to delamination often follows the Fracture Mechanics approach (Davies et al. 1998; Tay 2003).

Due to the behavior of the crack under load, three main modes of fracture can be distinguished: Mode I-clean tearing (crack opening)—stretching of the joint surfaces in opposite directions, perpendicular to the crack plane, Mode II-longitudinal shear-the fracture surfaces slide together as a result of the shear action applied parallel to the fracture plane, Mode III-transverse shear-the joint surfaces slide in a direction parallel to the front of the joint (Irwin 1957). In practice, they rarely occur independently, so mixed modes, e.g I + II, are more often encountered (Pereira and de Morais 2006).

During the brittle fracture of the laminate, i.e. during the propagation of the created gap, the potential energy of the system changes. The rate at which energy is released is called the energy release rate, $G_{\alpha}$, where $\alpha$ is the way the sample is loaded. The fracture will propagate until the energy release rate, $G_{\alpha}$, is equal to or greater than the critical value of fracture energy (toughness), $G_{\alpha c}$. The critical energy release rate, $G_{\alpha c}$, is a material constant that determines the 
resistance of a material to brittle fracture (Zehnder 2012; Gdoutos 2020).

The Double Cantilever Beam (DCB) test is nowadays standardized for the measurement of the mode I critical strain energy release rate, $\mathrm{G}_{\mathrm{Ic}}$, of unidirectional (UD) laminates (JIS K 7086:1993, ASTM D 5528-94a, ISO 15024:2001, Beckermann and Pickering 2015; Li et al. 2020; Cheng et al. 2020; Dadian et al. 2020). For mode II, various experiments have been proposed but it is not clear which is the best one (Davies et al. 1990, 1999), though the End-Notched Flexure (ENF, Fig. 2) test has been used the most (see e.g. Saidpour et al. 2003; Pereira et al. 2004; Campilho et al. 2010; Dourado et al. 2012; Beckermann and Pickering 2015; Cheng et al. 2020; Dadian et al. 2020; Shin et al. 2020). Although the ENF method has been designed for UD composites, it has been successfully applied to multidirectional (e.g. textile-reinforced) laminates (Pereira and Morais 2004; Rzeczkowski 2020).

Though RLR modifiers are available on the market and recommended by their manufacturers, there is a distinctive lack of information on the exact effects of the modifiers in a quantifiable manner. ENF is hereby tested as a method for quantifying the fracture toughness of toughened textile-reinforced epoxy laminates. This paper presents an investigation into Mode II fracture toughness, as measured by the ENF method, for glass-epoxy laminates modified with 2 different RLR modifiers. The aim is to assess in an objective and quantifiable manner the effect of resin modification by two of the RLR modifiers available on the market. Verification of the suitability of the ENF method and energy release coefficient approach in general is the primary goal, while the supply of data for fracture toughness of two specific combinations of resin and RLR is secondary to that. The primary innovation of the study is the appraisal of the suitability of the use of ENF test for the assessment of toughening efficacy in GFRP prepared from RLPmodified epoxy resin by way of the Mode II fracture toughness.

\section{Materials and methods}

\subsection{Resin and hardener}

The work uses epoxy resin Epidian 6 produced by CIECH Sarzyna S.A., Poland. Epidian 6 (bisphenol A diglycidyl ether) is a popular, inexpensive, versatile resin used for the production of laminates, adhesives, linings, coatings etc., cured at room or at elevated temperature. In the study, the Z-1 hardener from CIECH Sarzyna S.A., Poland, was used. It consists of triethylenetetramine (TETA), which is an aliphatic polyamine that reacts only with epoxy groups contained in the resin. Z-1 is used for room-temperature curing with the optional post-curing at elevated temperatures. Epidian 6 is by default mixed with the Z-1 hardener in 100:13 proportion (13 phr of hardener).

\subsection{Modifiers}

Two types of rubber modifiers were used in the work. Recommended amounts of $10 \%$ of each were mixed with epoxy resin to obtain a homogeneous solution.

The first of the modifiers used was ALBIPOX ${ }^{\circledR}$ 1000 by Evonik Nutrition \& Care GmbH. It is a resin based on bisphenol A, modified with elastomer, free of silicones. The used acrylonitrile-butadiene elastomer (NBR) is a special nitrile rubber chemically bonded to epoxy resin. During the curing of the resin, phase separation occurs, resulting in elevated properties for the final product.

The second used modifier is Hypro ${ }^{\circledR}$ 1300X16 ATBN, which is a low molecular weight acrylonitrilebutadiene (NBR) rubber terminated with an amino group. The modifier dissolves in the epoxy resin. During its hardening, discrete rubber particles precipitate, which absorbs the energy stored in the material during deformation. The amine structure in this modifier is based on $\mathrm{N}$-aminoethylpiperazine $(\mathrm{N}$ AEP).

\subsection{Laminates preparation}

Three resin compositions were prepared. One of them consists of neat epoxy resin-Epidian 6-with a hardener, while the other two have been modified with appropriate additives (Chap. 2.2). The individual compositions are summarized in Table 1. First the modifier is added to neat resin in the amount of $10 \%$ of the resin-mixture. Just before laminate manufacturing, the hardener is added in the amount of 13 parts per hundred parts resin or resin-modifier mixture.

The reinforcement of each laminate consisted of 6 layers of STR 024-500-110/125 woven roving 
Table 1 Resin and modifier compositions used in this study

\begin{tabular}{llll}
\hline $\begin{array}{l}\text { Component } \\
(\mathrm{g})\end{array}$ & $\begin{array}{l}\text { Composition 1-neat } \\
\text { Epidian 6 }\end{array}$ & $\begin{array}{l}\text { Composition 2-Epidian } \\
6+\text { Albipox 1000 }\end{array}$ & $\begin{array}{l}\text { Composition 3-Epidian 6 + Hypro } \\
\text { 1300X16 ATBN }\end{array}$ \\
\hline Resin & 100 parts $(88.5 \%)$ & 95 parts $(84.1 \%)$ & 95 parts $(84.1 \%)$ \\
Modifier & 0 & 5 parts $(4.4 \%)$ & 5 parts $(4.4 \%)$ \\
Hardener & 13 parts $(11.5 \%)$ & 13 parts $(11.5 \%)$ & 13 parts $(11.5 \%)$ \\
\hline
\end{tabular}

(Krossglass S.A., Poland) stacked with the same orientation $\left(\left[0^{\circ}\right]_{6}\right)$. The fabric used is a balanced, plain-weave woven roving with universal surface treatment.

Three laminates $230 \times 310 \mathrm{~mm}$ in size were manufactured following the guidelines of ASTM D7905/D7905M standard, one with each of the three resin compositions. Laminates were manufactured on glass plates using a hand lay up method, followed by vacuum bagging consolidation for increased fiber content in the composite.

Polyethylene insert was placed in the middle of the laminate thickness along the longer side. The inserts, which facilitated delamination under loading, were cut from a $30 \mu \mathrm{m}$ thick polyethylene foil. According to the standard, the thickness of the insert should not exceed $13 \mu \mathrm{m}$. However, it was impossible to obtain such a thin release film in the time available. The insert was folded in half along the longer side to obtain straight and even edge.

\subsection{Specimen preparation}

Before starting the test, the obtained laminates were sectioned into proper specimens. The ASTM D7905/ D7905M standard indicates that the part of the sample without the insert should be a minimum of $115 \mathrm{~mm}$, while the part with the insert minimum $45 \mathrm{~mm}$. From each of them, 5 specimens with approximate dimensions of $200 \times 25 \mathrm{~mm}$ and an insert length of about $70 \mathrm{~mm}$ were cut with a diamond saw. Then, on the long sides of the specimens, three vertical lines were marked perpendicular to the plane of the laminate at a distance of 20,30, and $40 \mathrm{~mm}$ from the beginning of the gap, respectively. They indicate the places where the force was applied during the calibration and the actual test. The prepared specimen is shown in Fig. 1.

\subsection{Determination of elastic modulus}

ASTM D7905/D7905M standard contain detailed instructions for procedures to be followed, as well as equations (Eqs. 1 through 6) to be used for calculations at each step. In order to determine the values of the flexural modulus, $E_{f}$, and the theoretical critical force, $P_{c}$ (the force at which the specimen should delaminate further when the axis of the lower support coincides with the corresponding line on the sample at a distance from the start of the insert of $a_{0}$ ), needed for further tests, a 3-point bending test, carried out in accordance with the ISO 178:2019 standard is performed on one sample from each laminate using an MTS Bionix ${ }^{\circledR}$ Servohydraulic Test Systems machine (support span $100 \mathrm{~mm}$, test speed $3 \mathrm{~mm} / \mathrm{min}$ ). The measurements were carried out until the linear dependence of the deformation on the applied force was obtained, consistent with Hooke's law. Flexural stresses (Eq. 1 after ASTM D7905/D7905M) and flexural strains (Eq. 2 after ASTM D7905/D7905M) are calculated:

$\sigma_{f}=\frac{3 P R}{2 B(2 h)^{2}}$

where $\sigma_{f}$ flexural stress (MPa), $P$ applied load (N), $R$ support span $(\mathrm{mm}), B$ specimen width $(\mathrm{mm}), 2 \mathrm{~h}$ specimen thickness $(\mathrm{mm})$.

$\varepsilon_{f}=\frac{6 s(2 h)}{R^{2}}$

where $\varepsilon_{f}$ flexural strain, $\mathrm{s}$ deflection $(\mathrm{mm}), 2 \mathrm{~h}$ specimen thickness (mm), R support span (mm).

The flexural modulus, $E_{f}$, was calculated from the Eq. (3) after ASTM D7905/D7905M:

$E_{f}=\frac{\sigma_{f 2}-\sigma_{f 1}}{\varepsilon_{f 2}-\varepsilon_{f 1}}$ 

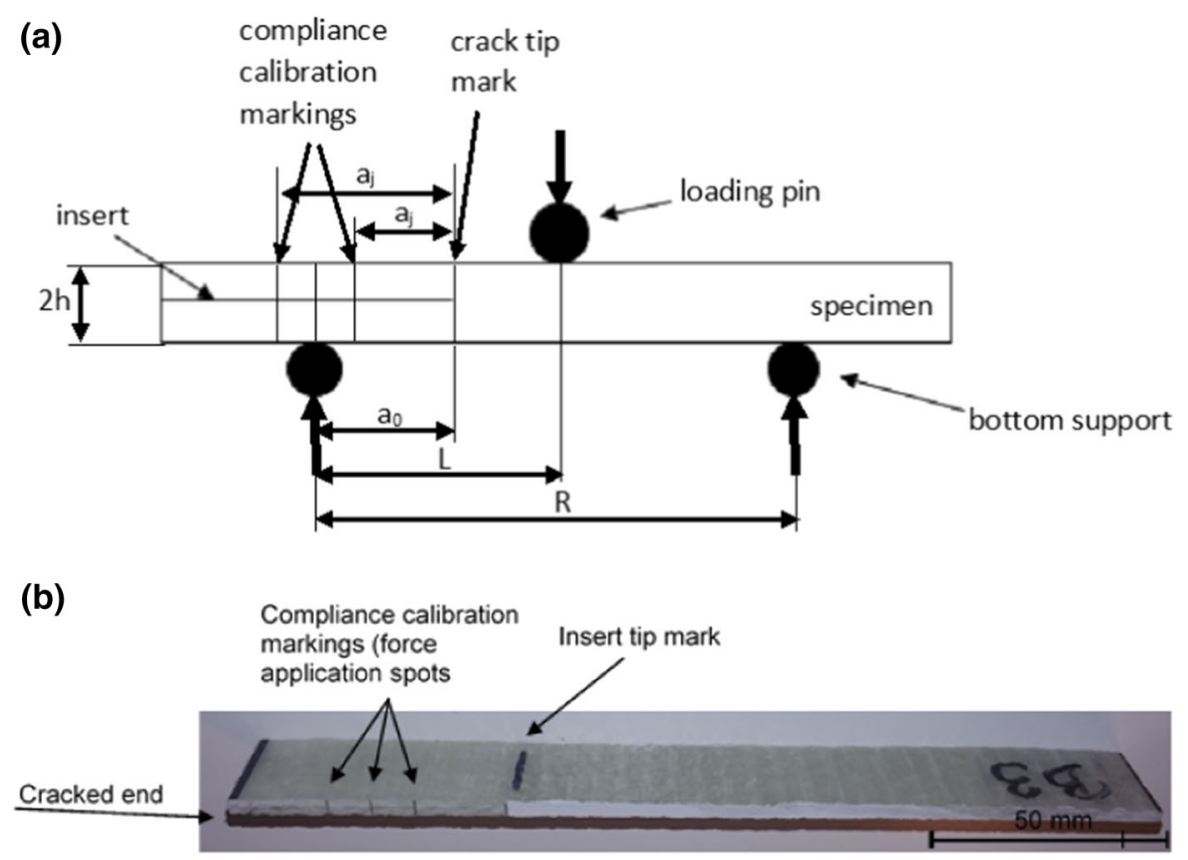

Fig. 1 End-Notched Flexure (ENF) specimen and loading method. a Schematics. $2 \mathrm{~h}$-specimen thickness; $a_{0}=30 \mathrm{~mm}$-initial delamination length used in the fracture test; $a_{j}=20 \mathrm{~mm}$ and $40 \mathrm{~mm}$ - crack length for compliance

where $\sigma_{f 1}$ flexural stress measured at $\varepsilon_{f 1}=0.0005$ $(\mathrm{MPa}), \sigma_{f 2}$ flexural stress measured with $\varepsilon_{f 2}=0.0025$ $(\mathrm{MPa})$.

The theoretical critical force, $P_{c}$, was calculated from the Eq. (4) after ASTM D7905/D7905M:

$P_{c}=\frac{4 B}{3 a_{0}} \sqrt{G_{I I c} E_{f} h^{3}}$

where $P_{c}$ theoretical critical force $(\mathrm{N}), B$ sample width $(\mathrm{m}), a_{0}$ initial delamination length used in the fracture test (m), $G_{I I c}$ energy release factor (from the literature) $\left(\mathrm{J} / \mathrm{m}^{2}\right), E_{f}$ flexural modulus $\left(\mathrm{N} / \mathrm{m}^{2}\right), h$ half the sample thickness (m).

\subsection{Non-precracked toughness}

The measurement is in essence a 3-point bending test, with the difference that the placement of the specimen was variable (Fig. 2). The distance between the lower supports remained the same, i.e. $100 \mathrm{~mm}$. For compliance calibration (NPC-CC), the specimen was placed so that the axis of one lower support was aligned with the line on the side of the specimen representing a distance of $20 \mathrm{~mm}$ from the start of the calibration; $L=50 \mathrm{~mm}$-distance between the bottom support and the loading pin; $R=100 \mathrm{~mm}$-support span. b Photograph of an actual specimen
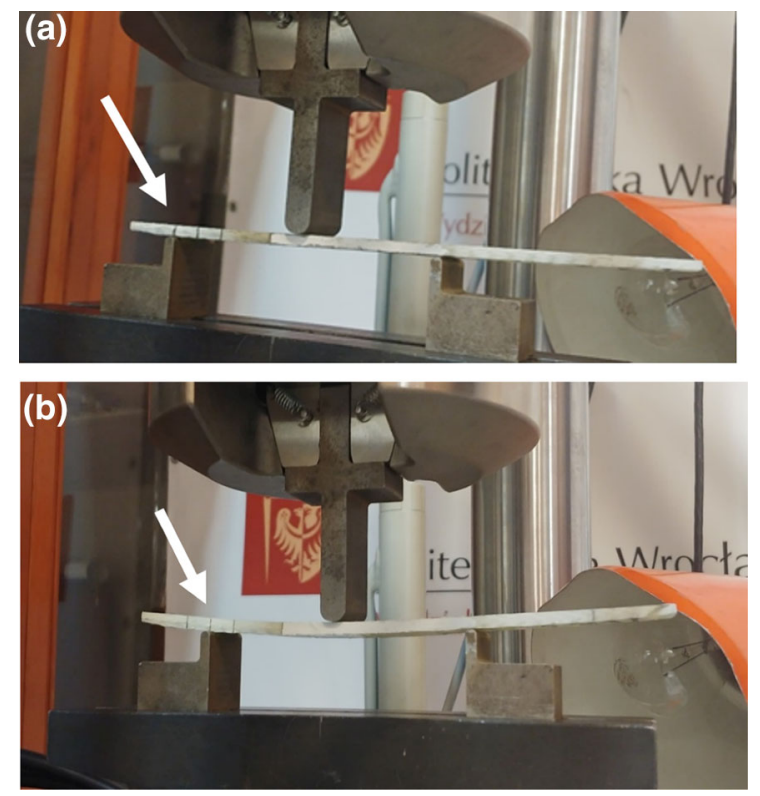

Fig. 2 Specimen in non-pre-cracked test. a during compliance calibration (NPC-CC) for $a_{O}=40 \mathrm{~mm}, \mathbf{b}$ during fracture test. Note the position of left lower support in relation to the marks on the edge of the specimen 
insert in the first test, and $40 \mathrm{~mm}$ in the second test. Specimens were loaded to $50 \%$ of the $P_{c}$, then unloaded. For the proper non-pre-cracked fracture test (NPC) axis of the lower support coincides with the distance of $30 \mathrm{~mm}$ from the beginning of the insert. In all cases loading and unloading was performed at a speed of $0.5 \mathrm{~mm} / \mathrm{min}$.

The first crack in the specimen during the actual test can be observed in two ways: visually and by force drop on the plot. The visual method of determining the maximum force, $P_{\max }$, could not be considered reliable. The better method is the one in which the crack was observed as a visible decrease in force on the recorded diagram (Fig. 3). Ideally, the line corresponding to the loading should grow linearly so that it drops off sharply in the course of the fracture. This is, however, often not the case because of the complicated nature of crack growth in polymeric materials (e.g. crazing, see Ehrenstein 2011).

To calculate the energy release factor, $G_{I I c}$, plot the displacement versus applied force during compliance calibration. Compliance, $C_{0}$, is reciprocal to the slope of the plot (Fig. 4). This is made thrice-for $a_{j \text { - }}$ $=20 \mathrm{~mm}$.and $a_{j}=40 \mathrm{~mm}$, and in the actual fracture test.

The compliance, $C_{0}$, was plotted against the delamination length cubed (Fig. 5). Linear regression of the plot yields calibration coefficients $A$ (y-intercept) and $m$ (slope).

The flexural modulus of elasticity $E_{l f}$ was calculated from Eq. (5) after ASTM D7905/D7905M:

$E_{l f}=\frac{L^{3}}{4 A B h^{3}}$

Fig. 3 Force-displacement relationship for one specimen example during the NPC fracture test (loading and unloading) where $E_{l f}$ flexural modulus (MPa), $L$ distance between the bottom support and the loading pin (mm), $A$ calibration factor $(\mathrm{mm} / \mathrm{N}), B$ sample width $(\mathrm{mm}), h$ half of the sample thickness (mm).

The energy release coefficient, $G_{I I c}$, for the specimen is calculated (Eq. 6 after ASTM D7905/ D7905M):

$G_{I I c}=\frac{3 m P_{\max }^{2} a_{0}^{2}}{2 B}$

where $G_{I I c}$ energy release coefficient $(\mathrm{N} / \mathrm{mm}), m$ calibration coefficient $\left(1 / \mathrm{Nmm}^{2}\right), P_{\text {max }}$ force at which the fracture occurred $(\mathrm{N}), a_{0}$ delamination length used in the actual test $(\mathrm{mm}), B$ sample width $(\mathrm{mm})$.

\section{Results and discussion}

Table 2 presents the calculated values of the flexural modulus and the theoretical critical force, $P_{c}$, for tested specimens.

Figures 6 and 7 present a comparison of the mean values of the energy release coefficients, $G_{I I c}$, forces at break, $P_{\max }$, and flexural modulus, $E_{l f}$ of non-precracked specimens of the tested laminates.

It is visible, both in Table 2 and Fig. 6, that the addition of $10 \%$ of RLR modifiers significantly (by about $22-26 \%$, T test returns $p$ values of 0.000815 and 0.000282 for Abipox 1000 and Hypro ATBN modified compositions, respectively) reduced the flexural modulus of elasticity of laminates made with the modified composition. That is contrary to what might generally be expected from both the literature and suppliers' promotional materials, though Unnikrishnan and

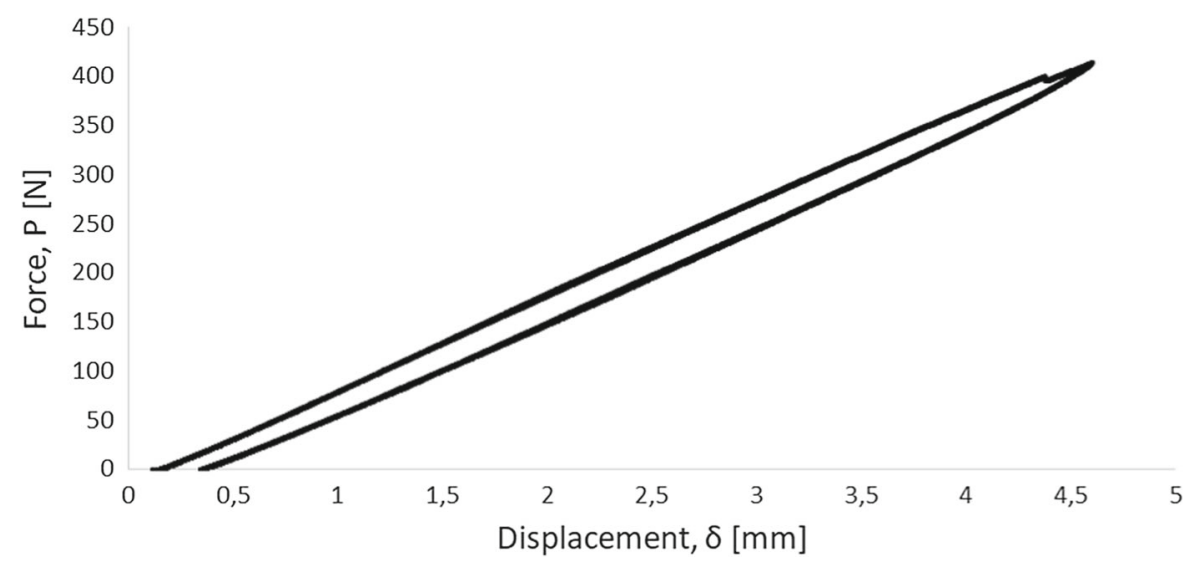


Fig. 4 Force-displacement relationship for compliance calibration of a specimen at $a_{j}=20 \mathrm{~mm}$

Fig. 5 Compliance dependence on delamination length
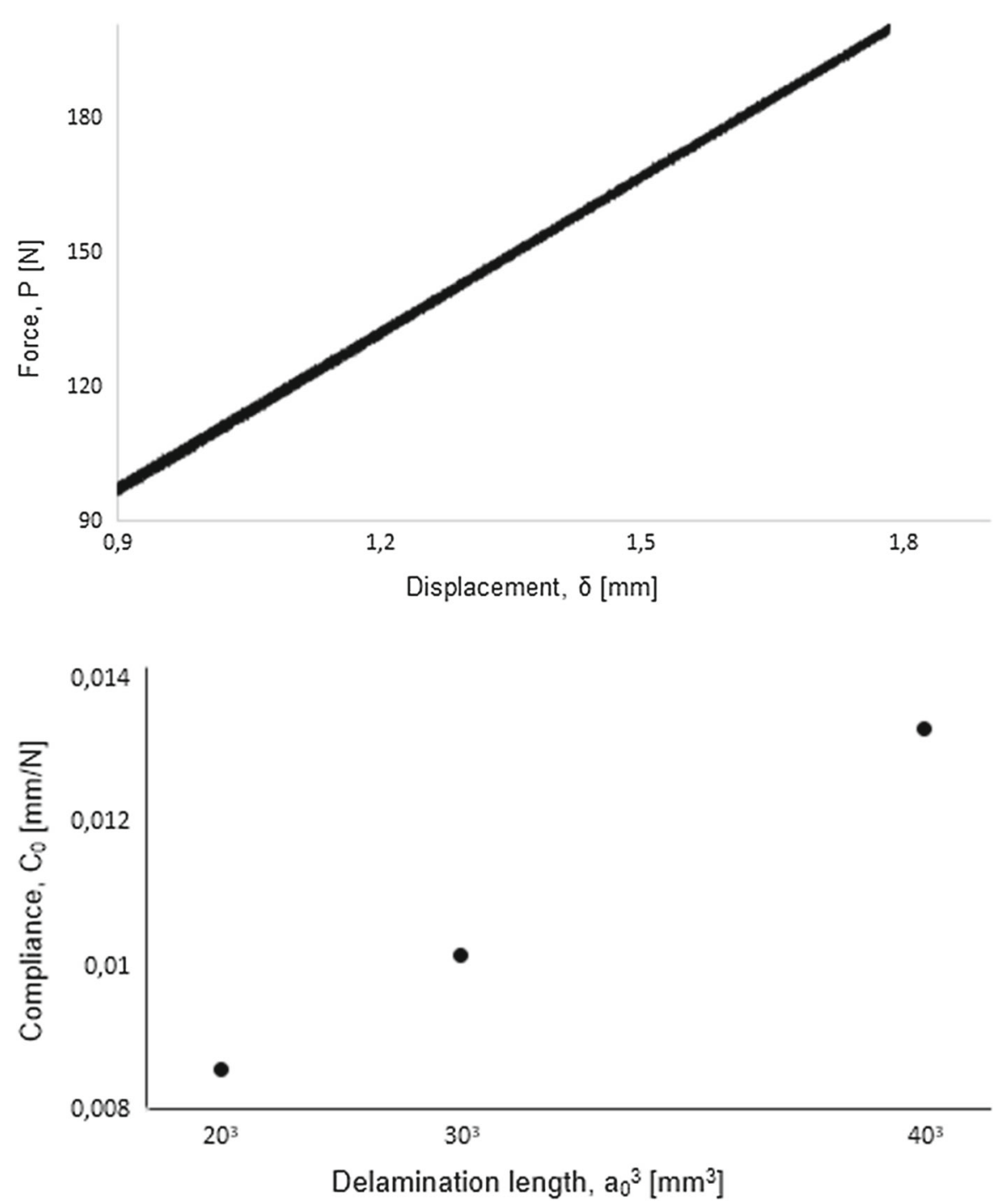

Table 2 Flexural modulus of elasticity and theoretical critical force values for specimens of tested compositions

\begin{tabular}{|c|c|c|c|c|c|c|}
\hline \multirow[t]{3}{*}{ Composition } & \multicolumn{3}{|c|}{$P_{c}(N)$} & \multirow[t]{3}{*}{$\varepsilon_{\mathrm{f}}$} & \multirow[t]{3}{*}{$\sigma_{\mathrm{f}}(\mathrm{Mpa})$} & \multirow[t]{3}{*}{$\mathrm{E}_{\mathrm{f}}(\mathrm{Mpa})$} \\
\hline & \multicolumn{3}{|c|}{$\mathrm{a}_{0}(\mathrm{~mm})$} & & & \\
\hline & 20 & 30 & 40 & & & \\
\hline \multirow[t]{2}{*}{ Composition 1 -neat Epidian 6} & 403 & 269 & 201 & 0.0005 & 3.03 & 6771.61 \\
\hline & & & & 0.0025 & 16.57 & \\
\hline \multirow[t]{2}{*}{ Composition 2-Epidian $6+$ Albipox 1000} & 330 & 220 & 165 & 0.0005 & 2.71 & 5737.98 \\
\hline & & & & 0.0025 & 14.19 & \\
\hline \multirow[t]{2}{*}{ Composition 3-Epidian $6+$ Hypro 1300X16 ATBN } & 375 & 250 & 188 & 0.0005 & 2.31 & 5609.70 \\
\hline & & & & 0.0025 & 13.53 & \\
\hline
\end{tabular}


Fig. 6 Flexural modulus $E_{l f}$ for each composition

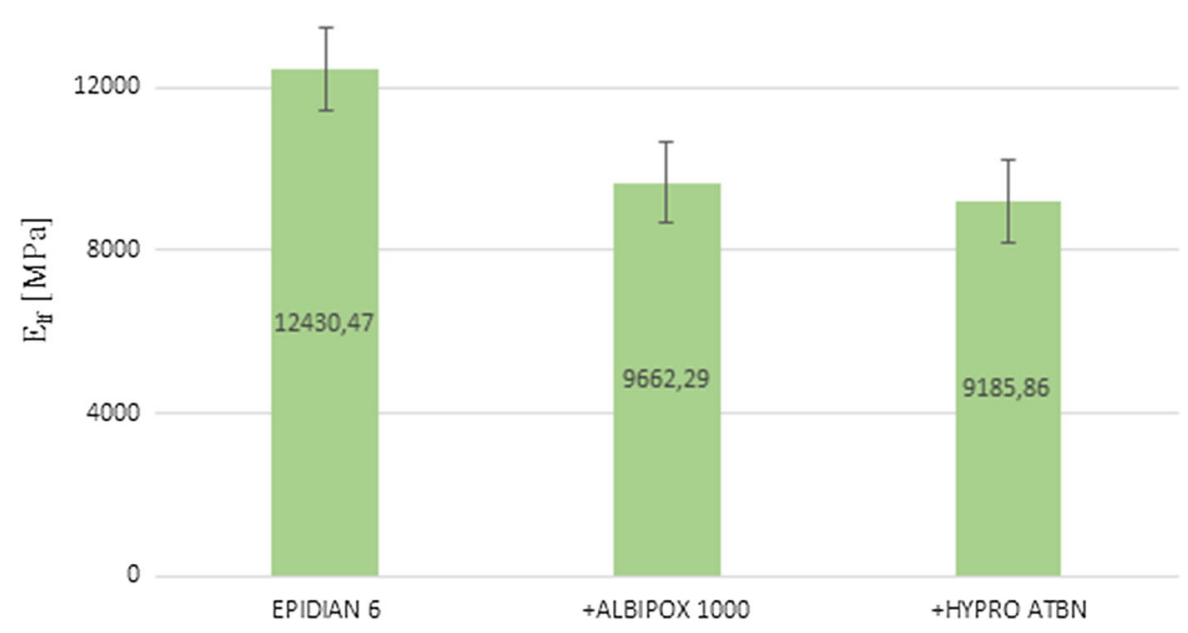

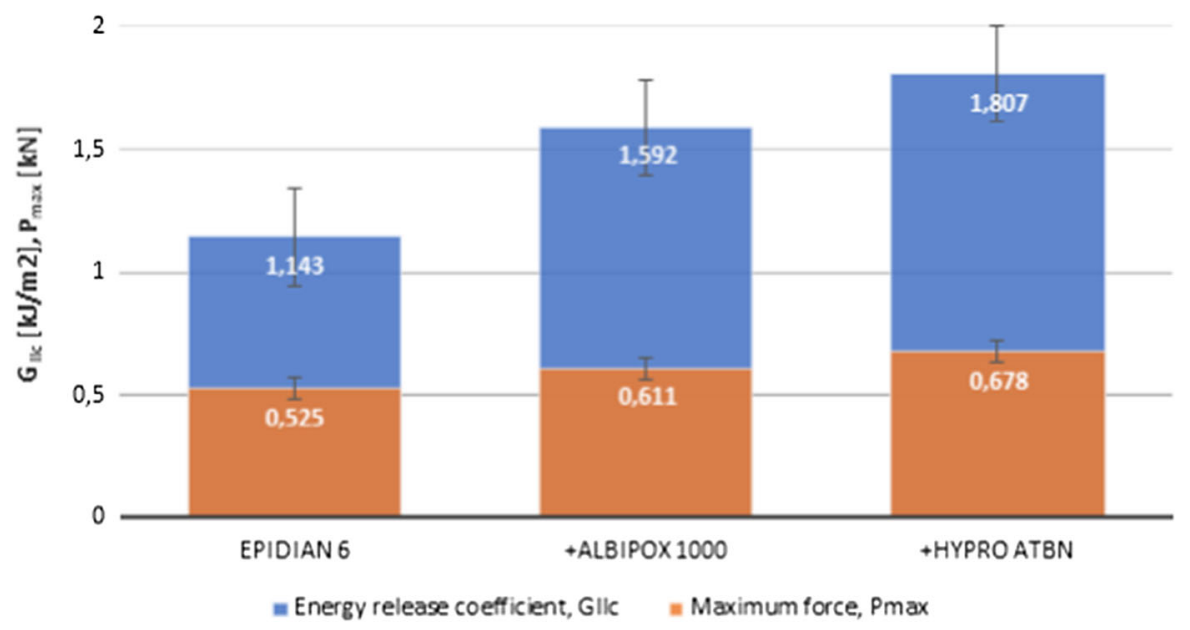

Fig. 7 Energy release coefficients $G_{I I c}$ and maximum forces (forces at break) $P_{\max }$ for each composition

Thachil (2006) do report examples of such reduction. The drop in modulus might be attributed to incomplete phase separation. Some of the rubber may remain dissolved in the resin, acting as an active (taking part in the curing-crosslinking reaction) plasticizer. That topic in itself is worth further investigation. As Unnikrishnan and Thachil (2006) note, both the modulus and strength reduction, as well as the toughening effect depend greatly on the chemistry of both the rubber and the resin (e.g. epoxy number and crosslinking density).

Figure 7 present the $G_{I I c}$ energy release coefficients calculated from the experiment. Both modifiers considerably increased the toughness of the composites of modified resins, by 39\% and 58\% for Albipox 1000 and Hypro 1300X16 ATBN, respectively. It is worth noting that the maximum force $P_{\max }$ also increased significantly (by $16 \%$ and $29 \%$, respectively; $p$ values 0.0386 and 0.0183 ) despite the reduction in the modulus. This demonstrates that modified materials can withstand significantly more deformation without initiation or propagation of cracks.

Surprisingly enough, the energy release coefficients themselves do not breach the significance thresholds. $\mathrm{T}$ test yields $\mathrm{p}$ values of 0.284 and 0.070 for compositions modified with Albipox 1000 and Hypro ATBN, respectively, when compared to composites of neat Epidian 6 resin. The most probable cause for low significance of $G_{I I C}$ when compared to the $P_{\max }$ is the variability of thickness between the specimens in case of laminates manufactured not in a stiff closed mold, while the specimen thickness is a significant input in 
the calculations. In case of testing the interlaminar fracture toughness of composites, it is effectively the matrix that undergoes fracture, while the majority of load in the composite (dictated by the moduli of fibers and matrix, which are an order of magnitude different) is carried by the reinforcing fibers, the amount of which do not differ. What differs is the volume fraction of fibers, which is lower in the thicker laminate with excessive resin content. This is also seen in the case of flexural strength of laminates, which is overly reliant on the thickness of the specimens, thus is susceptible to differences caused by the excess of resin in the composite. It is worth noting that majority of technologies for composite manufacturing control the amount of fibers being emplaced, not the amount of resin or the thickness of the element. This indicates a potential drawback of the energy release coefficient approach (originally devised for homogenous materials) for the quantification of the fracture toughness of composite materials, especially the Mode II fracture toughness as measured by the ENF method. Careful control of the thickness of laminates used in for this method is highly advisably to obtain meaningful results.

Overall, the toughness increase of modified materials is greater than the decrease in modulus, thus warranting the industrial use of such modifying agents to increase the dynamical properties of used materials.

\section{Conclusions}

A very important aspect when designing a machine or structure is its fracture resistance. Epoxy resin used commonly as a matrix for polymer composite materials has good handling properties but is too brittle. That is why various modifiers are used to increase the flexibility of products based on epoxy resin. This leads to two issues: how to efficiently increase the toughness of the resin without impacting significantly other properties, as well as how to measure the toughness in composite materials. This work presents the investigation of the use of the End-Notched Flexure test as a method for the assessment of toughening efficacy of RLP modification of glass-epoxy laminated composites. The laminates in question were prepared both with and without the addition of modifiers to the epoxy resin. The Mode II interlaminar fracture test is appraised as a potential standardized method for evaluating different toughening agents.

- The work has demonstrated a successful application of the ASTM D7905/D7905M standard EndNotched Flexure test to the measurement of the interlaminar toughness (here approximated by the energy release coefficient $G_{I I c}$ ) of multidirectionally reinforced layered composites. This method has the potential to become a useful comparative measure for the toughness of various laminates.

- Potential drawbacks of the End-Notched Flexure for the assessment of laminated composites are however indicated. Most laminated composites are manufactured in ways that control for the amount of fibers used, not the thickness of the laminate, while the results in ENF method, as in all flexural methods, are over-reliant on thickness of specimens.

- The results of the experiment demonstrated some of the drawbacks of reactive liquid rubber modification of epoxy resins, namely the reduction of the modulus of elasticity (flexural modulus in this case, though there is no reason to expect the tensile modulus to behave differently). The reduction is significant (on the order of 25\%).

- However, the experiment demonstrates also the benefits of the modification-toughness of the composites as measured by the $G_{\text {IIc }}$ energy release coefficient increased by ca. $40-60 \%$. The increase in toughness potentially outweighs the reduction of the modulus (and thus stiffness), thus warranting the use of such modifiers when necessary.

- The results are one addition to a greater database of modification results of various epoxy resins by various modifying agents. The effect depends greatly on the specific chemistry and properties of both the rubber and the resin, thus one set of results may not be universally applied to every modifier and every resin.

Author contributions Both authors contributed to the study conception and design. Material preparation, data collection and analysis were performed by Katarzyna Rybkowska and Michał Barcikowski. The first draft of the manuscript was written by Katarzyna Rybkowska and both authors commented on previous versions of the manuscript. Both authors read and approved the final manuscript. 
Funding This research received no external funding.

Data availability of data and material (data transparency) On request.

Code availability Not applicable.

\section{Declarations}

Conflict of interest The authors declare no conflict of interest.

Open Access This article is licensed under a Creative Commons Attribution 4.0 International License, which permits use, sharing, adaptation, distribution and reproduction in any medium or format, as long as you give appropriate credit to the original author(s) and the source, provide a link to the Creative Commons licence, and indicate if changes were made. The images or other third party material in this article are included in the article's Creative Commons licence, unless indicated otherwise in a credit line to the material. If material is not included in the article's Creative Commons licence and your intended use is not permitted by statutory regulation or exceeds the permitted use, you will need to obtain permission directly from the copyright holder. To view a copy of this licence, visit http://creativecommons.org/licenses/by/4.0/.

\section{References}

Abadyan M, Bagheri R, Kouchakzadeh MA, Hosseini Kordkheili SA (2011) Exploring the tensile strain energy absorption of hybrid modified epoxies containing soft particles. Mater Des 32:2900-2908. https://doi.org/10. 1016/j.matdes.2010.12.003

Barcikowski M, Królikowski W (2013) Effect of resin modification on the impact strength of glass-polyester composites. Polimery 58:450-460. https://doi.org/10.14314/ polimery.2013.450

Barcikowski M, Królikowski W, Lenart S (2017) Microstructures of unsaturated polyester resins modified with reactive liquid rubbers. Polimery 62:714-721. https://doi.org/10. 14314/polimery.2017.650

Beckermann GW, Pickering KL (2015) Mode I and Mode II interlaminar fracture toughness of composite laminates interleaved with electrospun nanofibre veils. Composites Part A 72:11-21. https://doi.org/10.1016/j.compositesa. 2015.01.028

Campilho RDSG, de Moura MFSF, Pinto AMG, Ramantani DA (2010) Interlaminar fracture characterization of a carbonepoxy composite in pure mode II. Mater Sci Forum 636-637:1518-1524. https://doi.org/10.4028/www. scientific.net/MSF.636-637.1518

Chae G-S, Park H-W, Lee J-H, Shin S (2020) Comparative study on the impact wedge-peel performance of epoxy-based structural adhesives modified with different toughening agents. Polymers 12(7):1549. https://doi.org/10.3390/ polym 12071549

Cheng C, Chen Z, Huang Z, Zhang C, Tusiime R, Zhou J, Sun Z, Liu Y, Yu M, Zhang H (2020) Simultaneously improving mode I and mode II fracture toughness of the carbon fiber/ epoxy composite laminates via interleaved with uniformly aligned PES fiber webs. Composites Part A 129:105696. https://doi.org/10.1016/j.compositesa.2019.105696

Chikhi N, Fellahi S, Bakar M (2002) Modification of epoxy resin using reactive liquid (ATBN) rubber. Eur Polym J 38:251-264. https://doi.org/10.1016/S00143057(01)00194-X

Crosbie GA, Phillips MG (1985a) Toughening of polyester resins by rubber modification. Part 1 mechanical properties. J Mater Sci 20:182-192. https://doi.org/10.1007/ BF00555911

Crosbie GA, Phillips MG (1985b) Toughening of polyester resins by rubber modification. Part 2 Microstructures. J Mater Sci 20:563-577. https://doi.org/10.1007/ BF01026527

Dadian A, Rahnama S, Zolfaghari A (2020) Experimental study of the CTBN effect on mechanical properties and mode I and II fracture toughness of a new epoxy resin. J Adhes Sci Technol 34:2389-2404. https://doi.org/10.1080/01694243. 2020.1763540

Davies P, Moulin C, Kausch HH, Fischer M (1990) Measurement of Gic and Gnc in carbon/epoxy composites. Compos Sci Technol 39:193-205. https://doi.org/10.1016/02663538(90)90041-3

Davies P, Blackman BRK, Brunner AJ (1998) Standard test methods for delamination resistance of composite materials: current status. Appl Compos Mater 5:345-364. https:// doi.org/10.1023/A:1008869811626

Davies P, Sims GD, Blackman BRK, Brunner AJ, Kageyama K, Hojo M, Tanaka K, Murri G, Rousseau C, Gieseke B, Martin RH (1999) Comparison of test configurations for determination of mode II interlaminar fracture toughness: results from international collaborative test programme. Plast Rubber Compos 28:432-437. https://doi.org/10. 1179/146580199101540600

Dourado N, Pereira FAM, de Moura MFSF, Morais JJL (2012) Repairing wood beams under bending using carbon-epoxy composites. Eng Struct 34:342-350. https://doi.org/10. 1016/j.engstruct.2011.09.001

Ehrenstein GW (2011) Polymer Werkstoffe. Struktur-Eigenschaften-Anwendung. 3. Auflage. Carl Hanser Verlag, Munich (in German)

Gdoutos E (2020) Fracture mechanics. An introduction. Springer, New York

Guo X, Xin J, Huang J, Wolcott MP, Zhang J (2019) Preparation and toughening of mechanochemically modified ligninbased epoxy. Polymer 183:121859. https://doi.org/10. 1016/j.polymer.2019.121859

Irwin G (1957) Analysis of stresses and strains near the end of a crack traversing a plate. J Appl Mech 24:361-364

Januszewski R, Dutkiewicz M, Nowicki M, Szołyga M, Kownacki I (2021) Synthesis and properties of epoxy resin modified with novel reactive liquid rubber-based systems. Ind Eng Chem Res 60:2178-2186. https://doi.org/10.1021/ acs.iecr.0c05781

Kaynak C, Cagatay O (2006) Rubber toughening of phenolic resin by using nitrile rubber and amino silane. Polym Test 25:296-305. https://doi.org/10.1016/j.polymertesting. 2006.01.004 
Kinloch AJ, Mohammed RD, Taylor AC, Eger C, Sprenger S, Egan D (2005) The effect of silica nano particles and rubber particles on the toughness of multiphase thermosetting epoxy polymers. J Mater Sci 40:5083-5086. https://doi.org/10.1007/s10853-005-1716-2

Kostański LK, Królikowski W (1985) Elastomer-Modified Polyester Resins. Int Polym Sci Technol 12:T/131-T/136

Li Z, Wang Y, Cao J, Meng X, Aamir RM, Lu W, Suo T (2020) Effects of loading rates on mode I interlaminar fracture toughness of carbon/epoxy composite toughened by carbon nanotube films. Composites Part B 200:108270. https://doi. org/10.1016/j.compositesb.2020.108270

McBain DS (1996) Unsaturated polyester resins (toughening with elastomers). In: Salamone JC (ed) Polymeric materials encyclopedia. CRC Press, Rochester, pp 8486-8488

Ochelski S (2004) Metody doświadczalne mechaniki kompozytów konstrukcyjnych. WNT, Warsaw (in Polish)

Ozturk A, Kaynak C, Tincer T (2001) Effects of liquid rubber modification on the behaviour of epoxy resin. Eur Polym $\mathrm{J}$ 37:2356-2363. https://doi.org/10.1016/S00143057(01)00158-6

Pereira AB, de Morais AB (2004) Mode II interlaminar fracture of glass/epoxy multidirectional laminates. Composites Part A 35:265-272. https://doi.org/10.1016/j.compositesa. 2003.09.028

Pereira AB, de Morais AB (2006) Mixed mode I + II interlaminar fracture of glass/epoxy multidirectional laminates-Part 2: experiments. Compos Sci Technol 66:1896-1902. https://doi.org/10.1016/j.compscitech. 2006.04.008

Rzeczkowski J (2020) An experimental analysis of the endnotched flexure composite laminates beams with elastic couplings. Contin Mech Thermodyn. https://doi.org/10. 1007/s00161-020-00903-2
Saidpour H, Barikani M, Sezen M (2003) Mode II interlaminar fracture toughness of carbon/epoxy laminates. Iran Polym J 12:389-400

Shin YC, Lee WI, Kim HS (2020) Mode II interlaminar fracture toughness of carbon nanotubes/epoxy film-interleaved carbon fiber composites. Compos Struct 236:111808. https://doi.org/10.1016/j.compstruct.2019.111808

Sultan JN, McGarry FJ (1973) Effect of rubber particle size on deformation mechanisms in glassy epoxy. J Polym Sci 13:29-35. https://doi.org/10.1002/pen.760130105

Szymańska J, Bakar M, Białkowska A, Kostrzewa M (2018) Study on the adhesive properties of reactive liquid rubber toughened epoxy-clay hybrid nanocomposites. J Polym Eng 38:231-238. https://doi.org/10.1515/polyeng-20170099

Tay T (2003) Characterization and analysis of delamination fracture in composites: an overview of developments from 1990 to 2001. ASME Appl Mech Rev 56:1-32. https://doi. org/10.1115/1.1504848

Ullet JS, Chartoff RP (1996) Unsaturated polyester resins (toughening with liquid rubber). In: Salamone JC (ed) Polymeric materials encyclopedia. CRC Press, Rochester, pp 8489-8496

Unnikrishnan KP, Thachil ET (2006) Toughening of epoxy resins. Des Monomers Polym 9:129-152. https://doi.org/ $10.1163 / 156855506776382664$

Zehnder AT (2012) Fracture mechanics. Springer, Netherlands

Publisher's Note Springer Nature remains neutral with regard to jurisdictional claims in published maps and institutional affiliations. 